\title{
Japanese scientists begin closed debate on size of contribution to SSC
}

Tokyo. The obscure process by which Japan will decide whether to invest as much as $\$ 2$ billion in the US Superconducting Super Collider (SSC) lurched forward last week as a working group of the Council of Science and Technology, Japan's highest science policy-making body that is chaired by the prime minister, began closed-door hearings on the issue. But it seems that those in charge have no better idea about the likely outcome than the rest of the world.

There are several government-related bodies involved in the process, which is expected to be completed by the end of the year. The working group of the Council of Science and Technology headed by Wataru Mori, a former president of Tokyo University, heard testimony from a handful of scientists representing all sides of the issue. At the same time, a group of US and Japanese bureaucrats meeting as part of an agreement reached early this year by the Japanese prime minister, Kiichi Miyazawa, and the US president, George Bush, is looking into the technical aspects of collaboration.

Mori and Jiro Kondo, president of the Science Council of Japan and a member of the working group, would not speculate on the outcome of their deliberations. Mori does not know even if the recommendations of the scientists will be combined with those of the international working group before they are submitted to the prime minister.

The majority of Japanese scientists are opposed to joining the SSC under the terms put forward by the United States, namely, that Japan must contribute a substantial amount to its construction. But the bureaucrats are more likely to be influenced by the fact that Bush has endorsed the project and has personally urged Miyazawa to do likewise.

Akira Itoh, director of superconductivity in the Agency of Industrial Science and Technology of the Ministry of International Trade and Industry, who serves on the USJapan working group, says that the majority of Japanese high-energy physicists want to participate in the SSC project. But in fact that support comes from only a minority of the country's high-energy physicists, mostly senior scientists who will retire before the proton-proton collider is built (see Nature 358, 266; 1992).

The science council, some 210 academics elected by scientific societies to advise the government, debated the SSC at its general assembly last year but reached no conclusion. Kondo, wishing to act before Bush visited the country in January, wrote his own unfavourable recommendation to the prime minister after clearing it with one of the council's steering committees.

Kondo says that his recommendations, presented in person to Miyazawa, say that the SSC is an important tool for basic science but that Japan must first improve its own domestic research. Kondo says Miyazawa thanked him for his recommendations and said that Kondo's comments are the first advice on the SSC that he has received from Japanese scientists.

The recent visits to Japan by officials of the European Laboratory of Particle Physics (CERN) seeking Japanese support for the planned European Large Hadron Collider (LHC) (see Nature 359, 5; 1992) has prompted other senior Japanese university professors to speak their minds on the SSC. One adviser to the Science and Technology Agency and the Ministry of Education, Science and Culture, says he worries that the SSC issue may tear apart the Japanese scientific community. He says that if Japan contributes to the SSC for political reasons, it should do so in a way unrelated to science.

David Swinbanks

\section{China juggles economic growth and basic research}

Beijing. A new five-year programme to strengthen China's economy is the latest example of a struggle by scientists around the world to preserve adequate funding for basic research.

The initiative, called the Climbing Programme, was conceived by the State Science and Technology Commission with support from the country's State Education Commission, the National Natural Science Foundation and the Chinese Academy of Sciences. Each of 30 projects will receive 1 million yuan (US\$200,000) a year for five years, and the overall programme will involve some 6,000 scientists and engineers.

On the surface, the programme represents a major commitment to basic research. Each project satisfies at least one of four criteria: it represents frontier research; it contributes to China's economic development; it draws on the country's unique natural resources, geography or cultural heritage; and it advances a field in which China is already pre-eminent. The projects were chosen by a 45-member committee of scientists and science administrators led by Zhang Chun$\mathrm{Hao}$, director of the science foundation.

Ten of the projects cover work in such rapidly expanding fields as high-tempera- ture superconductivity and molecular biology; eight projects, including those involving nanomanufacturing and high-yield, highly resistant crops, are expected to have important commercial applications. Another eight examine the ecosystem of the QinghaiTibetan plateau, the world's youngest mountain range, and Jingluo, a traditional approach to medical science, for example, while the remainder cover areas, including mathematical proofs by computer, in which Chinese scientists are recognized as world leaders.

Yet basic research remains on a precarious footing in China, which invests only 0.7 per cent of its gross national product on research, far below the average for the industrial world. The president of the Chinese Academy of Sciences, Zhou Guang-Zhao, believes that one-third of the academy staff should leave their laboratories and take up applied work in industry. Just last month, he told a national symposium on production and research that "as long as a high-quality research community is maintained, China's basic research will not be affected by encouraging researchers to enter the main battlefield of economic development".

There is also considerable unhappiness over how the final round of proposals was selected for the Climbing Programme. With 172 projects competing for 18 remaining slots, the selection committee gave outstanding scores to 25 . However, government officials could not be persuaded to expand its quota of winners, and seven worthy projects were arbitrarily dropped. In addition, the National Natural Science Foundation approves only one in four applications, despite an estimate by officials that almost half of them are excellent proposals that deserve funding.

This unhappiness surfaced unexpectedly during a planning meeting for the Climbing Programme. In a breach of Chinese etiquette, Wang Gan-Chang, a prominent member of the Chinese academy and a co-founder of a high-technology project launched in 1986, confronted Song Jian, director of the State Science and Technology Commission, with the accusation, "Where were you earlier?". Song replied that what matters most is "the present".

Despite these concerns, the government has repeatedly said that it intends to reward innovative and first-class science. The Climbing Programme is seen as one step on that road to excellence.

You Qin Li 